\title{
Focus on the morphogenesis, fate and the role in tumor progression of multivesicular bodies
}

\author{
Xueqiang Peng, Liang Yang, Yingbo Ma, Yan Li and Hangyu Li id
}

\begin{abstract}
Multivesicular bodies (MVBs) are endosome organelles that are gradually attracting research attention. Initially, MVBs were considered as important components of the endosomal-Iysosomal degradation pathway. In recent years, with an increase in extracellular vesicle (EV) research, the biogenesis, fate, and pathological effects of MVBs have been increasingly studied. However, the mechanisms by which MVBs are sorted to the lysosome and plasma membrane remain unclear. In addition, whether the trafficking of MVBs can determine whether exosomes are released from cells, the factors are involved in cargo loading and regulating the fate of MVBs, and the roles that MVBs play in the development of disease are unknown. Consequently, this review focuses on the mechanism of MVB biogenesis, intraluminal vesicle formation, sorting of different cargoes, and regulation of their fate. We also discuss the mechanisms of emerging amphisome-dependent secretion and degradation. In addition, we highlight the contributions of MVBs to the heterogeneity of EVs, and their important roles in cancer. Thus, we attempt to unravel the various functions of MVBs in the cell and their multiple roles in tumor progression.
\end{abstract}

Keywords: Multivesicular body, Extracellular vesicles, Amphisome, Autophagy, Trafficking, Release, Cancer

\section{Background}

Multivesicular bodies (MVBs) are organelles defined by a single membrane, which typically have a diameter of about $250 \mathrm{~nm}$ to $1000 \mathrm{~nm}$, and contain smaller $50-80 \mathrm{~nm}$ diameter intraluminal vesicles (ILVs). Morphologically, most MVBs are round or slightly elliptical [1-5]. They were first discovered in the nervous system in the 1950s, and the "gold standard" definition is based on their ultrastructural morphology [3, 4]. Altick et al. systematically elaborated the distribution, protein content, and trafficking function of MVBs in neurons, and further revealed the classification, function, and properties of MVBs in the hypoglossal nerve $[3,4]$. Notably, the discovery of MVBs has expanded from the original nervous system to the entire life domains, including mammals, plants, fungi, and other organisms,

\footnotetext{
* Correspondence: sj_li_hangyu@sina.com

Department of General Surgery, The Fourth Affiliated Hospital, China Medical University, Shenyang 110032, China
}

and they are highly conserved in both yeast and mammalian systems $[3,6,7]$. The typical roles of MVB is to participate in protein trafficking in the endocytic system and to regulate homeostasis of the endosomal-lysosomal pathway $[2,8]$. However, as research has progressed, the focus has shifted to the cell microenvironment, leading to the discovery that the microenvironment contains an abundance of meaningful extracellular vesicles (EVs), which can significantly change the behavior of target cells, especially in the tumor microenvironment [9-12]. Importantly, the fusion of MVBs with the plasma membrane then releases ILVs into the extracellular space as exosomes [13-15].

The contents of mature MVBs are generally divided two broad categories: constitutive molecules and cargo molecules [3, 4]. The constitutive molecules are essential for the organelle function, constituting the organelle structure or serving MVBs functions, which includes endocytic processes, vesicle budding, sorting functions, 
and numerous signaling molecules involved in the regulation of MVB fate [16, 17]; for example, endosomal sorting complex required for transport (ESCRT), ceramide, tetraspanin proteins (CD81, CD9, CD37, and CD63), small GTPases (Rabs), and synaptosomalassociated proteins (SNAREs) [18, 19]. On the one hand, the cargo molecules might comprise factors derived from MVB sorting, including processed and transported membrane-bound receptors, ligands, internalized proteins, and macromolecules. On the other hand, the cargoes may comprise active proteins, nucleic acids, lipids, and/or substances recruited from the cytoplasm [2, 20-23]. Different subpopulations of MVBs consist of different constituent molecules, and exert different physiological and pathological effects [21, 23-25]. Unfortunately, there have been few studies on the variations in MVB morphology and distribution. The distribution and content level of MVBs show significant heterogeneity in a variety of cells and pathological processes $[2,3,26,27]$. In this review, we systematically summarize the origin of MVBs, and the mechanisms of cargo sorting and MVB fate regulation. We also discuss the contributions of MVBs to the heterogeneity of EVs. Finally, the effects of MVBs on cancer progression are summarized.

Not surprisingly, it seems that only a comprehensive disclosure of MVB involved in the endosomal-lysosomal system degradation and the selectivity of diverse cargoes loading of MVB for discharging their ILVs into the extracellular space as exosomes mechanisms [14, 28-30]. We can have a more multifaceted understanding of the role of MVBs in cancer growth and metastasis to provide new ideas for further manipulation of MVB fates $[9,24]$.

\section{MVB biogenesis}

Originally, it was believed that endocytosis and Golgi secretion were sorted into special early endosomes with different cargoes, and then, the early endosomes were thought to internalize and form ILVs under an endosomal sorting complex required for transport (ESCRT) to form mature MVBs [1, 31-33]. Misfolded proteins, signalling receptors, and related factors were thought to be sorted into MVBs and then degraded into lysosomes to maintain intracellular material balance and homeostasis [11, 22, 29, 33-35]. However, further in-depth research showed that eukaryotic MVBs serve as key components of the plasma membrane quality control system by identifying and degrading cell surface proteins and intracellular misfolded proteins [25, 33, 36-38]. Moreover, MVBs selectively load specialized substances (lipids, proteins, and nucleic acids) and then fuse with the plasma membrane to release their exosomes [13, 19, 39, 40] (Fig. 1). Importantly, how are mature MVBs formed? Studies have demonstrated that early endosomes in the endosomal system gradually generate ILVs under an ESCRT-dependent or ESCRT-independent mechanism, and the formation of mature MVBs is a critical first step in this process [31, 41, 42].

\section{The ESCRT-dependent mechanism}

MVB biogenesis requires mechanisms to create distinct domains along the endosomal membrane and further produces ILVs [2, 43, 44]. ESCRT complexes (ESCRT-0, -I, -II, and -III) and ESCRT-III-associated proteins (e.g., vacuolar protein sorting gene 4 (VPS4) and ALIX (disassembly complex)) have been further studied [2, 43]. Briefly, ALIX and ESCRT-I/ESCRT-II are directly involved in membrane budding, and ESCRT-III and the AAA-ATPase VPS4 subsequently cut the bud from the cytoplasm to form ILVs $[43,45,46]$. The specific functions and structure of the ESCRT subunits have been further studied [43, 47]. During the formation of ILVs, the coordinated binding of VPS4 to ESCRT-III drives vesicle neck contraction [31, 43]. The number of ILVs was significantly reduced in cells with double mutations of VPS2 and Snf7 (ESCRT-III), while showing a larger ILV neck, and the whole process was inseparable from the synergistic effect of VPS4 in yeast [31]. Interestingly, Wenzel et al. confirmed that one ESCRT wave results in the formation of a single ILV at a time via observing the number of ILVs at different time points after EGF stimulation correlated well with the number of waves observed from live-cell imaging at the corresponding time points [44]. In addition, they also revealed that clathrin not only plays a role in endocytosis, but is also located on the MVB membrane where it seems to interfere with HRS membrane localization, which further affects the formation of ILVs [44].

\section{The ESCRT-independent mechanism}

The biogenesis of ESCRT-independent ILVs involves a mechanism in which ceramide induces vesicle bending and budding [42, 48-50]. Activation of Gi-coupled sphingosine 1-phosphate (SP1) receptors on MVBs is essential for cargo sorting into the ILVs destined for exosome release [48]. Proteolipid protein is transferred to distinct subdomains on the endosomal membrane, and then exosome-associated domains are transferred into the lumen occurs in an ESCRT-independent manner, which also requires the sphingolipid ceramide [49]. Im et al. [50,51] depleted the ESCRT subunits and also inhibited ceramide activity, confirming that sulfamethoxazole regulated ESCRT-dependent MVB biogenesis and secretion. In fact, the ceramide-mediated mechanism may be relatively independent of ESCRT-dependent ILV biogenesis; however, studies have shown that ESCR T-mediated cargo sorting can synergize with ceramideinduced lipid curvature to produce vesicles that share 


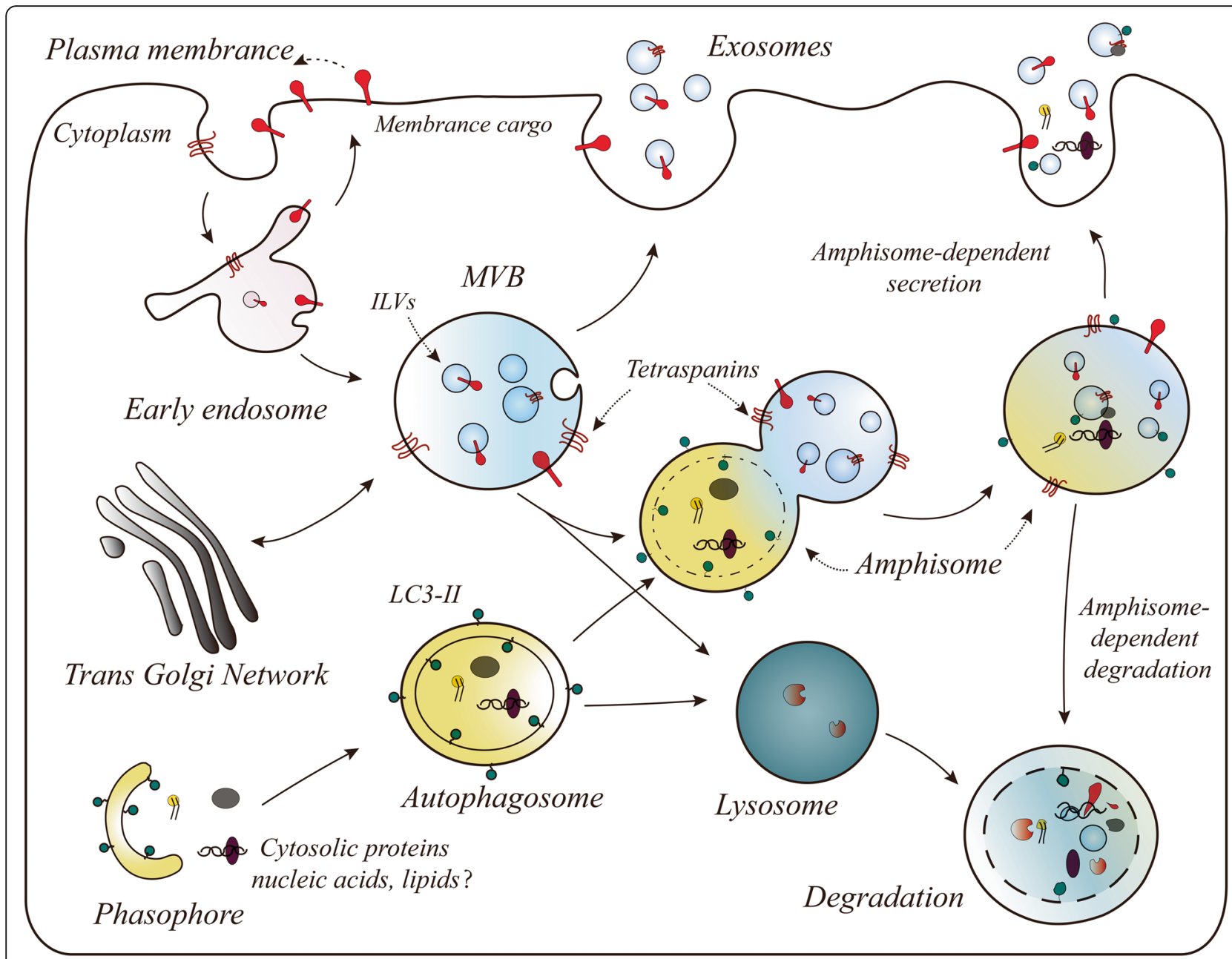

Fig. 1 (Multivesicular body) MVB morphogenesis and possible sorting pathways: exosome release, back-fusion, and degradation in the lysosome and amphisome-dependent degradation or secretion. (1) the MVB may fuse with the plasma membrane and release the ILVs as exosomes. (2) Membrane cargo (ligand/receptor) may be recycled back to the plasma membrane or may be targeted to ILVs in the MVB. (3) MVBs can target internalized membrane cargoes (ligand/receptors) for degradation in the lysosome by fusing with lysosomes. (4) The amphisome fuses with lysosomes to form the autolysosome for degradation of cargo, or fuses with the plasma membrane, triggering extracellular component release, including dsDNA, proteins and lipids and separately, ILVs act as exosomes

both ESCRT-dependent and -independent mechanisms $[19,49,50]$. Interestingly, other mechanisms for ILVs biosynthesis have been proposed $[26,52,53]$. Natural adiponectin has a multimeric structure, and adiponectin and T-cadherin play key roles in membrane filling, which can significantly induce ILV biogenesis [26]. In addition, adiponectin possibly enhances ILV formation via a mechanism that is independent of ceramide and ESCRT [26, 43]. Notably, syndecans, via their attached heparan sulfate polysaccharide chains, bind to their cytoplasmic junction syntenin to participate in the formation of ILVs [54]. Syntenin also interacts directly with ALIX through the three LYPX $_{\mathrm{n}} \mathrm{L}$ motifs, and in turn, ALIX can bind to ESCRT-III, thereby creating the machinery critical for cargo deposition into the ILVs of the MVBs [53-55]. Moreover, syntenin-ALIX exosome biogenesis and budding into MVBs can be controlled by ADP ribosylation factor 6 and phospholipase D2 [53]. Of interest, tetraspanins, including CD63, CD9, CD81, and CD82, comprise integral membrane proteins that are highly enriched in exosomes, $[23,41,56]$. Association with tetraspanins has emerged as completely independent of the ESCRT-dependent and ceramide sorting mechanisms for promoting entry into the MVBs $[23,56]$.

\section{Sorting of cytoplasmic cargoes into MVBs}

Notably, active substances released in the cytoplasm might need to be recruited close to the MVB membrane to be sequestered into the ILVs $[57,58]$. However, how these substances are sorted into MVBs remains largely unknown. 


\section{Protein cargoes}

Post-translational modifications (PTMs) of proteins participate in the loading of specific elements into the ILVs of MVBs [58, 59]. In particular, ubiquitin and ubiquitin-like modifiers are major controllers of protein loading in MVBs $[58,59]$. A recent study showed that ubiquitin-like 3 (UBL3) modification controls protein sorting into MVBs [58]. However, does a cytoplasmic protein need to be sorted into a specific membrane region via specific transporter recognition after PTMs [58]? Interestingly, a new mechanism has been identified for proteins harbouring a KFERQ motif, enabling their binding to heat shock protein 70 (HSP70), which is involved in the delivery of endosomal microautophagy (eMI)-dependent cytoplasmic proteins to MVBs in an ESCRT dependent manner [60, 61]. Furthermore, wnt induces the arginine-methylated proteins, glycogen synthase kinase 3 (GSK3) and protein arginine methyltransferase 1 to be encompassed within a membrane-bound organelle, which is also translocated into MVBs in an eMI-dependent manner [62]. Recent studies suggest that autophagic substrates (p62) can enter MVBs via the eMI pathway via a rapid starvation reaction that depends on ESCRT-III and VPS4 [63, 64]. In addition, another study revealed that a protein complex, made of two hydrolytic enzymes and the autophagic adaptor NBR1, is delivered into ILVs inside MVBs in the ubiquitination and ESCR T-dependent mechanism. This specific mechanism has been termed the NVT pathway (NBR1-mediated vacuolar targeting) $[61,65,66]$. Notably, the mechanisms of the eMI and NVT pathways respectively address the cytoplasmic proteins either in the lumen of the forming ILVs or in the lumen of the MVB outside of the ILVs $[61,66]$. Obviously, it is worth noting that these mechanisms (eMI and NVT) of MVB formation/loading are more likely to target lysosomal pathway degradation processes, whereas the mechanism of the exosomal protein recruitment has not yet been completely characterized.

\section{Nucleic acid cargoes}

Notwithstanding, exosomal RNAs are able to modulate pathophysiological processes, and the mechanisms controlling specific RNA sorting into MVBs are just beginning to be understood [20,67-71]. Based on RNA structures, accumulating evidence suggests that RNAs with the same motif sequences may be targeted to ILVs via RBPs (RNA-binding proteins) [13, 20, 68, 72]. For example, cytosolic Y-box protein 1 (YBX1) can recognize specific motifs mRNAs and selectively package these RNAs into ILVs [20]. Furthermore, heterogeneous nuclear ribonucleoprotein A2B1 (hnRNPA2B1) can derive the loading of exosomal microRNAs into MVBs by binding to specific Exo-motifs [73]. Major vault protein (MVP) can package miR-193a into exosomes leading to the reduction of cytoplasmic miR-193a via forming an MVP protein-miR-193a complex [72]. It has been reported that RISC, argonaute 2 (Ago2) and GW182 can be combined with packaged RNAs into ILVs [13, 67, 74]. Endosomal membranes are also involved in regulating the formation and turnover of the RISC complex, which is beneficial for RISC to continuously recruit target RNA into MVBs $[13,75]$. Moreover, a study showed that the KRAS proto-oncogene GTPase (KRAS) inhibits the sorting of Ago2-dependent miRNAs into MVBs [67]. Weaver et al. further revealed the existence of KRAS-dependent sorting of multiple RNAs [74]. An additional mechanism for nucleic acid cargo sorting into ILVs involves the NURR (N-terminal unit for RNA recognition) domain of SYNCRIP (synaptotagmin-binding cytoplasmic RNA-interacting protein), which directly targets miRNAs containing hEXO motifs into ILVs [68]. In addition, Hobor et al. revealed that the molecular basis of Syncrip-mediated special RNA loading into ILVs, which was recognition of the miRNA targets is mediated by the cooperation between a NURR RNAbinding domain and three RNA recognition motifs (RRMs) in Syncrip [76]. However, the commonly reported exosomal RBPs examined (Ago, hnRNPA2B1, PARK7/DJ1, GAPDH, and MVP) were absent from classical exosomes when standard purification methods were performed, suggesting that potential RBPs and RNA isolation mechanisms or are necessary processes when RNA is loaded into MVBs [13].

Most researchers' research on the mechanism of RNA loading into ILVs has focused on the recognition and recruitment of specific RNA motifs by RNA-binding proteins (see above). There are few studies on how RNA is sorted into specific regions of an MVB and then is incorporated into ILVs. Several studies have demonstrated that in transporting RNA to MVBs is probably dependent on the ability hnRNPA2B1 to travel along the cytoskeleton [73]. YBX1 may participate in miRNA loading into ILVs through ubiquitin modification and/or direct binding to components of the ESCRT mechanism or other ubiquitin-modified integral membrane proteins [43, 77]. Notably, transported by RBPs, RNA continuously interacts with the outer (cytoplasmic) surface of MVBs. Importantly, RNAs with higher affinity for raftlike regions of the MVB limiting membrane are retained at the membrane and then loaded into ILVs through different internalization mechanisms [71, 78]. Therefore, we can speculate that RNA molecules initially engage MVBs and then are incorporated into ILVs in a process that largely depends on the modification and regulation of the RBPs, specific RNA sequence motifs and affinity for membrane lipids. Surprisingly, many previous studies believed that microRNAs are mainly stable inside exosomes. A recent study by Rong $\mathrm{Xu}$ et al. [79] reported 
that a large number of exosomal miRNA species bound to RBPs can reside on the outer surface of the vesicle. Although there are few reports of microRNAs on the surface of exosomes, recent studies have revealed that microRNA may adhere to the outer membrane of exosomes. There is no doubt that the determination of microRNAs on the exosome surface will have an important impact will have on the study of RNA loading mechanisms and exosomemediated miRNA cell-cell communication.

\section{Fates of MVBs}

MVB biogenesis may progress through one of two maturation or sorting stages, comprising direction to lysosomes where their content is degraded, reaching the cell surface where they fuse with the plasma membrane for exosome release [4, 36, 80] (Fig. 1). Therefore, a deeper understanding of the switch that determines the fate of MVBs is required, which could lead to control of the fate of MVBs. In this review, we will focus on the transport of MVBs to the plasma membrane for the release of ILVs. The ultimate fate of MVBs involves two consecutive steps: critically targeted trafficking and fusion with the biological membrane; however, the effectors involved in targeting MVBs to the lysosome or the plasma membrane are different [81-83]. Accumulating evidence has revealed the complexity of the control of MVB fate. Here, we summarize data from studies of the important factors of MVB fate. However, the different classifications have overlapping areas, indicating the complexity of MVB fate determination (Fig. 2).

\section{MVB trafficking}

The targeted movement and regulation of MVBs are key factors in determining their fate, which not only requires the dynamic action of molecular motors (kinesins, dynein, and actin-based myosin motors), but also the microtubule cytoskeleton, which serves as a "railroad" for trafficking [11, 84-88]. The transport of MVB-

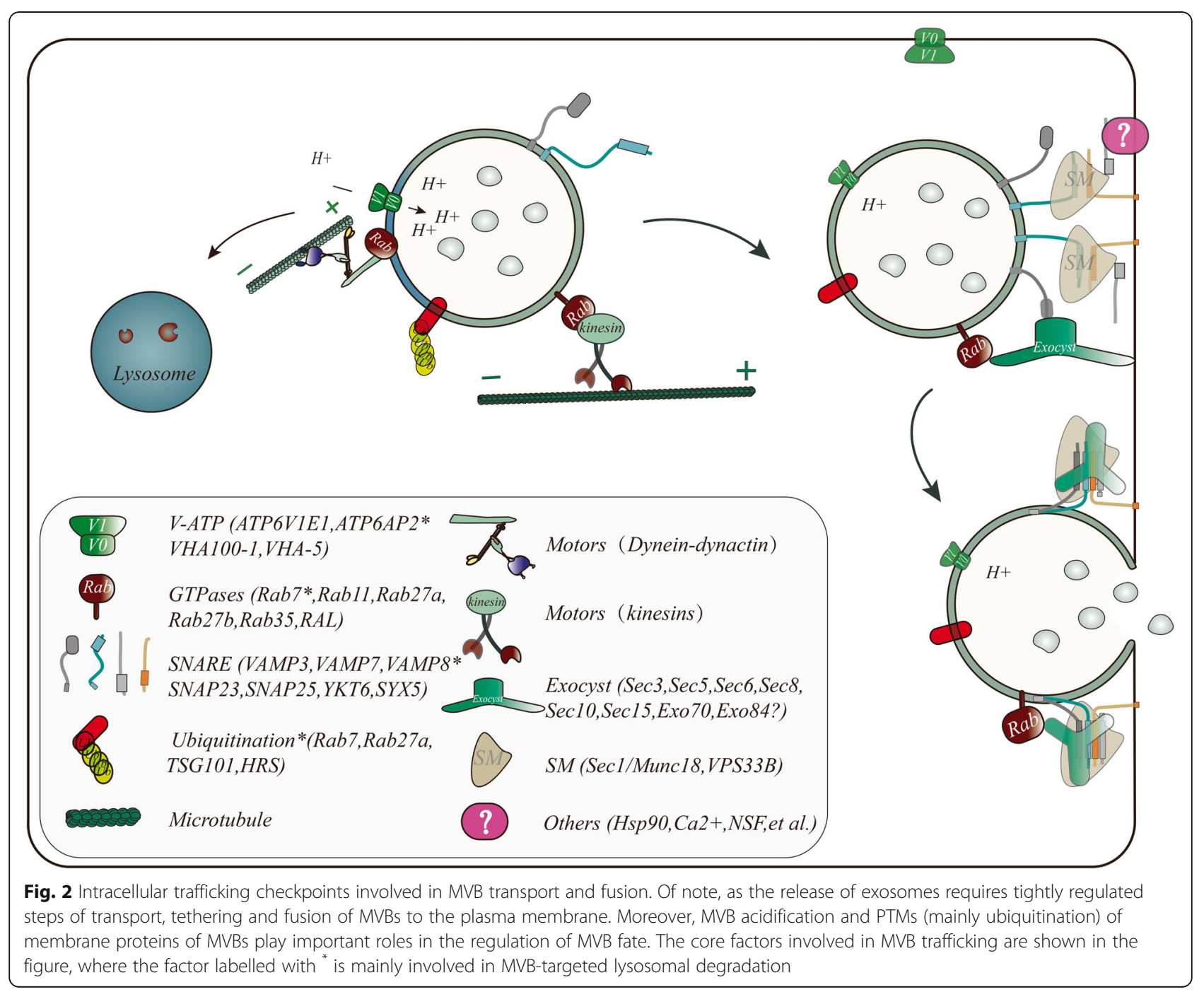


dependent molecular switches (small GTPases) along the microtubule network to its terminus, after balancing the dynamics and resistance, ultimately achieves the MVB docking and fusion with the target membrane [36, 87, 89] (Fig. 2).

By recruiting of various effector proteins, members of the Rab family of small GTPases serve as multifaceted organizers of almost all membrane trafficking processes in eukaryotic cells [32, 90-93]. Importantly, further indepth analysis showed that small GTPases (Rab27, Rab35, Rab11, Rab7, and RAL-1) play well-established roles in MVB trafficking or docking to the plasma membrane for exosome release [51, 69, 89, 91-95]. Rab27 (Rab27 and Rab27b) and their effectors Slp4, Slac2b, and Munc13-4 play roles in MVB biogenesis and trafficking [89, 92, 96]. For example, loss of Rab27a or Rab27b function alters MVB morphology and docking to the plasma membrane, resulting in a significant drop in exosome production [92]. The Rab27a effector munc13-4 also regulates the secretion of exosomes via the $\mathrm{Ca}_{2}{ }^{+}$-induced Rab11-dependent MVB trafficking pathway, which influences upstream of exosome release [89, 92].

Molecular motor proteins play key roles in MVB trafficking, which including kinesin heavy chains (KIFs), the cytoplasmic dynein heavy chain, and the actin cytoskeleton and its associated myosin motors [36, 95, 97]. Generally, kinesin motors drive MVB transport from the minus-end to the plus-end (centrifugal transport), while the cytoplasmic dynein motor drives MVB transport in the opposite direction (centripetal transport) [36, 95] (Fig. 2). For example, kinesin family proteins (KIFs) and cytoplasmic dyneins are essential for outward or inward cellular prion protein $\left(\operatorname{PrP}^{\mathrm{C}}\right)+\mathrm{MVB}$ trafficking, respectively [36]. Importantly, Heisler et al. confirmed that muskelin, binds to cytoplasmic dynein, is necessary for $\mathrm{PrP}^{\mathrm{C}+}$ MVB inward trafficking and degradation [36]. In addition, Sinha et al. confirmed that cortactin (actin cytoskeletal regulatory protein) can bind to the branched actin nucleating Arp2/3 complex and further control both trafficking and plasma membrane docking of MVBs [84]. The difference in mechanisms is that actin-binding cortactin regulates the MVB-targeted plasma membrane, whereas the muskelin-dynein interaction controls the lysosomal targeting of $\operatorname{PrP}^{\mathrm{C}}$-containing MVBs [36, 84].

However, other evidence supports the concept that PTMs of membrane proteins of MVBs play important roles in the regulation of MVB fate [33, 81, 82, 98] (Fig. 2). ISGylation (the conjugation of proteins with interferon stimulated gene 15 (ISG15)) of the MVB protein TSG101 induces its aggregation and degradation, which significantly impairs exosome secretion [81]. Similarly, Chakrabarti showed that mahogunin triggers the fusion of amphisomes and MVBs with lysosomes via the ubiquitination of TSG101, and is involved in the degradation of abnormal proteins in cells [98]. Interestingly, KIBRA (a scaffold protein in various cell processes) inhibits the proteasomal degradation of Rab27a by inhibiting the ubiquitination of Rab27a, which promotes exosome secretion [82]. Ubiquitin-specific protease 32 (USP32) can control the recycling and release of MVBs through deubiquitylation of Rab7 [99]. Similarly, Anderson et al. confirmed that phosphatidylinositol-4-phosphate 5-kinase type 1 gamma (PIPKIyi5) and sorting nexin 5 (SNX5) prevent HRS ubiquitination, which facilitates HRS sorting EGFR into MVBs and targeting to lysosomes [33]. Thus, the PTMs of MVB membrane proteins (such as TSG101, Rab27a, Rab7, and HRS) are important for the regulation of MVB fate, which may be an effective target for manipulating the fate of MVBs.

\section{Fusion of MVBs with the plasma membrane}

MVBs dock at the plasma membrane and ultimately complete membrane fusion to achieve exosome release $[16,100,101]$. In this review, we mainly discuss the factors that regulate MVB and plasma membrane-fusion events. Several lines of evidence support the notion that the assembly and cycling of a functional SNAREpin consisting of one R-SNARE (mostly v-SNARE) and three Q-SNAREs (mostly t-SNARE) that combine with each other to catalyze the fusion process $[16,101]$ (Fig. 2). Notably, the same SNARE proteins are not constitutively expressed in all cell types, which implies that each cell type may adapt a unique functional SNAREpin for its own membrane-fusion events $[17,101,102]$. The pairing of distinct SNAREs determines the specificity of the fusion, which most likely depends on the organism, cell type, or MVB subtype [16, 17, 101, 103]. It is currently believed that the process involves the following successive steps or simultaneous steps.

Numerous studies have demonstrated that Rab GTPases play active roles in SNAREpin formation. This is exemplified by Rab27a and its effectors, which, in addition to mediating vesicle-motor attachment, also control exocytic vesicle docking at the plasma membrane [90, 92, 100, 101]. The Rab27a effector interacts directly with the SM protein (sec1/munc18), which induces the docking of exocytic vesicles to the plasma membrane [90, 92]. Moreover, Rab27a silencing reduced the docking of MVBs and increased their size, which implied that the loss of Rab27a caused MVBs to fail to fuse with the plasma membrane and derives the MVBs fused to each other to become larger $[1,69,90,92]$. In contrast, Rab27b seems to interfere with the intracellular polar distribution and targeted transport of MVBs [92]. Mammalian target of rapamycin (mTORC1) regulates exosome release through a Rab27a-dependent mechanism in HeLa cells [27]. In contrast, experiments have 
also shown that, in epithelial cells (ECs) and HepG2 cells, mTORC1 can promote exosome release by inducing the expression and colocalization of vesicle-associated membrane protein 3 (VAMP3) and SNAP23 [12, 94].

The docking and tethering of MVBs to the plasma membrane is also inseparable from the exocyst complex [100, 103] (Fig. 2). In the exocyst complex, Sec3 directly interacts with $S s o 1 / 2$ to promote the initial assembly of the Sso-Sec9 t-SNARE complex and stimulate membrane fusion [100]. However, RAL1mediated MVB plasma membrane fusion acts independently of the exocyst, and an active form of RAL-1 could derive or recruit syntaxin 5 (SYX5) aggregates on the apical plasma membrane to promote MVB fusion, thereby inducing exosome release [1]. In addition, SYX5 silencing induced an accumulation of MVBs under the plasma membrane in mammals [1]. Importantly, actin can also induce MVB plasma membrane docking and fusion [84, 86]. Especially, invadopodia (plasma membrane extensions), specialized invasive actin structures, play key roles at docking and secretion sites for CD63-and Rab27a-positive MVBs [85], and invadopodia biogenesis and matrix-degrading activities are inextricably involved with VAMP7 and SNAP23 complexes [84]. In summary, the SNARE complex is at least partially involved in the formation of invadopodia, which indirectly affect the secretion of exosomes, suggesting that there may be a positive feedback mechanism involving the SNARE complex and invadopodia that has an important role in the secretion of tumor exosomes [84, 85] (Fig. 3a). Furthermore, pyruvate kinase type $\mathrm{M} 2$ and histamine can promote the fusion of MVBs with the plasma membrane via the phosphorylation of SNAP23 at serine 95 or serine 110 in tumor cells, respectively $[14,15]$. Notably, the process of MVB docking and fusion in various cell types is induced by $\mathrm{Ca}_{2}{ }^{+}$, which may play a role in the activation of functional Rab and SNARE proteins (see above) [38, 89, 93]. Remarkably, HSP90 can also directly interact with and deform membranes via a conserved amphipathic helix, which suggests that its unique membrane-deforming function may provide the driving force for the fusion of the plasma membrane and MVBs and thus the release of exosomes [104].

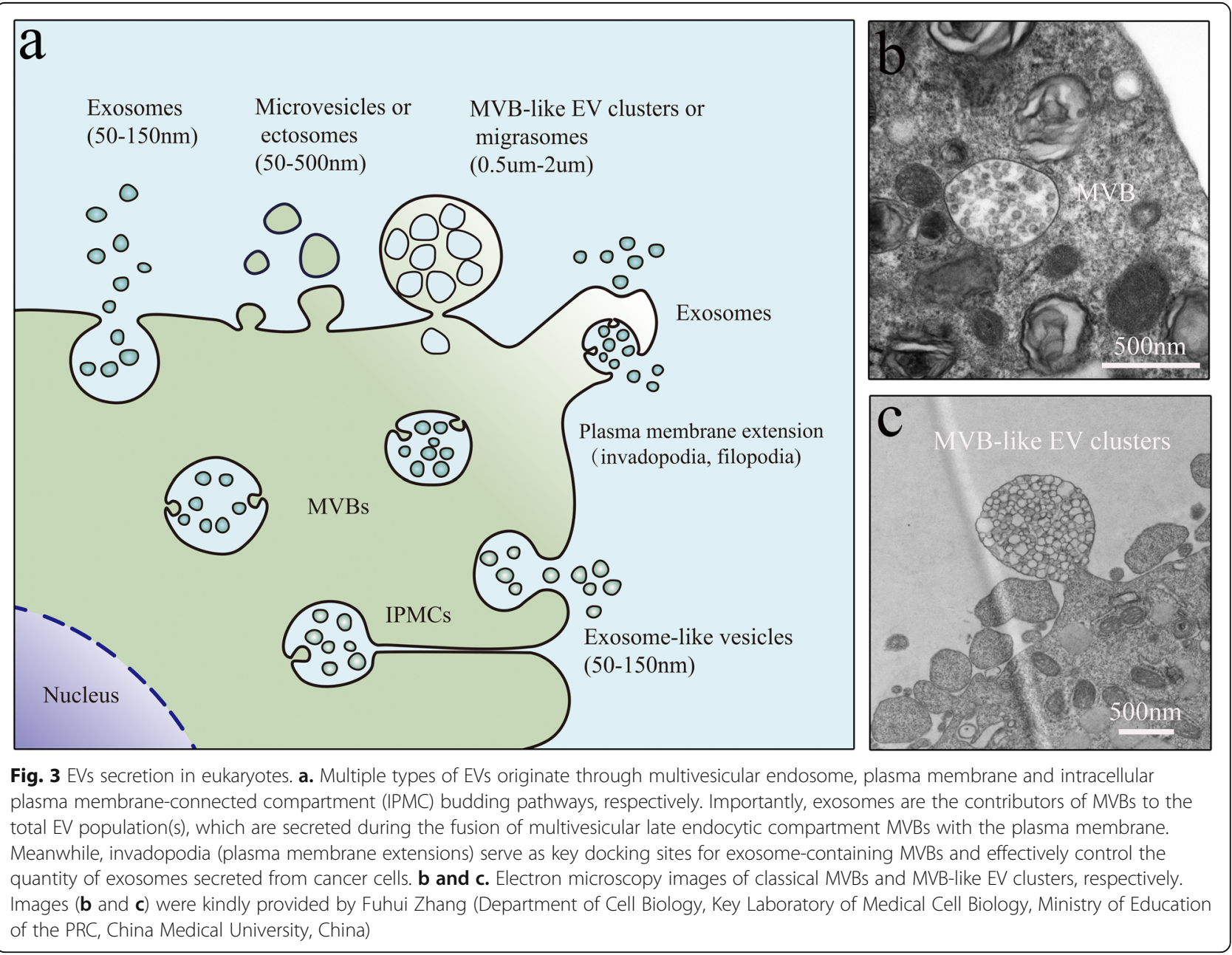


The ATPase N-ethylmaleimide-sensitive factor (NSF) and its adaptor protein disassemble the SNARE complex to recycle SNARE for another round of fusion, which is a necessary step in the fusion cycle $[16,101,103,105]$. The SM protein is involved in SNARE-dependent membrane fusion [101, 105-107]. Studies have shown that VPS33B, which contains a sec1-like domain, is a regulator of SNARE-mediated membrane fusion in arthrogryposisrenal dysfunction-cholestasis (ARC) syndrome [106]. Additionally, in hematopoietic stem cells (HSCs), VPS33B interacts with the Rab11a/Rab27a pathway to promote the secretion of exosomes [105]. The SM protein family may be involved in MVB transport by coordinating SNAREs serving multiple roles in fusion events $[105,107]$. The vATPase and two-pore channels (TPCs), localized on the surface of endosomes and lysosomal systems, are involved in the regulation of the fate of MVBs in an acidificationdependent manner [108-111]. Moreover, these findings revealed that the intracellular vesicle $\mathrm{pH}$ can directly affect the final fate of intracellular vesicles, with a higher MVB $\mathrm{pH}$ facilitating its targeting to the plasma membrane [14, 109] (Fig. 2). In addition, the v-ATPase proton pump activity-independent v-ATPase subunit might act downstream of SNARE and participate in a late critical step of MVB-plasma fusion [111, 112]. Interestingly, in flies, depletion of VHA100-1 leads to vesicle accumulation in synaptic terminals, suggesting a defect in the release of MVBs [112]. Moreover, the abnormal function of VHA-5 (the largest subunit of the $\mathrm{V}_{0}$ ATPase) also led to abnormal MVB accumulation, which affected MVB docking and membrane fusion [113].

\section{The crosstalk between MVBs and autophagy}

With the deepening of recognition of the eukaryotic endosomal membrane system, MVB biogenesis and autophagic flow also play an important role in responding to stress and maintaining cell homeostasis in pathological processes. What is the relationship between the autophagy and endocytic processes? One of the typical fates of MVBs involves autophagosomes or lysosomes in the degradation of MVB cargoes [81, 114]. Evidence has demonstrated that secretory autophagy plays an important role in unconventional protein secretion and exerts a key regulatory influence on diseases, especially tumors [114-116]. Recently, high-mobility group box 1 , released by autophagic cancerassociated fibroblasts, was observed to maintain the stemness of luminal breast cancer cells [116]. Amphisomes, formed by the fusion of autophagosomes and MVBs in the rat liver, have been characterized in indirect, but not functional terms [117]. In recent years, amphisomes have garnered extensive interest. In K562 cells, Fader et al. found that induction of autophagy or overexpression of LC3 promoted the fusion of MVBs with autophagic vacuoles and inhibited exosome release [118].
However, several lines of evidence support the idea that MVB fusion with autophagosomes to form amphisomes that can also target the plasma membrane for the release of EVs [13, 37, 38, 64, 83, 119, 120]. Inhibition of PIKfyve (phosphoinositide kinase, FYVE-type zinc finger containing) using apilimod or its depletion in PC-3 cells increased the secretion of exosomes and induced secretory autophagy and observed a small population of p62-labelled electron dense structures together with CD63-containing exosomes, implying that these pathways are tightly linked [64]. This result have been caused by impaired fusion of lysosomes with MVBs or autophagosomes, which possibly increased the fusion of MVBs with autophagosomes, suggesting that cells maintain their homeostasis by secreting the contents of these vesicles $[64,119]$. The release of EVs containing SNCA (alpha-synuclein) was facilitated by the inhibition of the autophagy-lysosome pathway in human neuroglioma cells, and transmission electron microscopy (TEM) confirmed that amphisomes served as novel secretory organelles in this regulation of cellular homeostasis [119, 120]. Notably, mechanical stress can induce autophagy component release via sEVs through the amphisome pathway [38]. More importantly, Jeppesen et al. confirmed that active secretion of cytosolic DNA occurs through an amphisome-dependent mechanism in DKO1 cells [13]. In summary, these studies revealed that there is an intrinsic and complex crosslinked relationship between MVBs and autophagy. Amphisomes are formed by the fusion of MVBs with autophagosomes and not only participate in MVB degradation, but are also secreted into the microenvironment to participate in broader cell-cell communication [34, 121-123]. Previously, scholars believed that this mechanism belonged to one of the types of secretory autophagy [60, 124]. However, in recent years, several lines of evidence have supported the notion that the secretion or degradation via an amphisome-dependent mechanism might exist [125-129] (Fig. 1, Table 1). Obviously, this complex interrelationship between MVBs and autophagy requires further exploration.

\section{The contributions of MVBs to the heterogeneity of EVs}

There is mentioning of the ongoing debate on the contributions of MVBs to the total EV population(s) [13, 17, 19, 69, 130] (Fig. 3). Indeed, extracellular vesicles constitute a heterogeneous population of membrane vesicles in various modes of biogenesis. Extracellular vesicle size may varies (typically 50-500 $\mathrm{nm}$ but as large as $10 \mu \mathrm{m}$ ), including microvesicles [131], microparticles, ectosomes [132], MVB like structures (Fig. 3a,c) (migrasomes [133], multivesicular cargo [134], and MVB-like EV clusters [135]), and arrestindomaincontaining protein 1 (ARRDC1)mediated 
Table 1 Secretion or degradation of cargo through an amphisome-dependent mechanism

\begin{tabular}{|c|c|c|c|c|}
\hline Authors/Years & Cargoes & Cell lines & Amphisome's judgment & Ref \\
\hline \multicolumn{5}{|l|}{$\begin{array}{l}\text { Secretion of cargo through } \\
\text { an Amphisome-Dependent } \\
\text { Mechanism }\end{array}$} \\
\hline Dennis K. Jeppesen et al./2019 & $\mathrm{dsDNA}$ and histones & DKO-1, Gli36 & SIM, Colocalization (CD63、LC3) & [13] \\
\hline Kaizhe Wang et al./2019 & Autophagy-associated proteins & Hela, MDA-MB-231 & TEM, Colocalization (CD63、LC3) & [38] \\
\hline Sandra Atienzar-Aroca et al./2018 & VEGFR2 & ARPE-19 & TEM & [125] \\
\hline Georgia Minakaki et al./2018 & SNCA/alpha-synuclein & Human neuroglioma cells & TEM & [120] \\
\hline Elisabet Barbero-Camps et al./2018 & Amyloid beta (Ab) & Neuron-rich primary cultures & - & {$[37]$} \\
\hline Ying-Da Chen et al./2017 & Annexin A2 & Human lung epithelial cells. & Colocalization (CD63、LC3) & [126] \\
\hline Nina Pettersen Hessvik et al./2016 & $\begin{array}{l}\text { Autophagy-associated protein } \\
\text { (NBR1, p62, LC3, WIPI2 etc) }\end{array}$ & PC-3 & TEM & {$[64]$} \\
\hline \multicolumn{5}{|l|}{$\begin{array}{l}\text { Degration of cargo through } \\
\text { an Amphisome-Dependent } \\
\text { Mechanism }\end{array}$} \\
\hline Amengual J et al./2018 & Apolipoprotein B100 & Huh7 & Colocalization (EEA1、LC3) & [127] \\
\hline Jakob Mejlvang et al./2018 & $\begin{array}{l}\text { Autophagy receptors p62/SQSTM1, } \\
\text { NBR1, NDP52, NCOA4 }\end{array}$ & A549, BJ & $\begin{array}{l}\text { Immuno-EM (p62), Colocalization } \\
\text { (Rab5、LC3) }\end{array}$ & {$[63]$} \\
\hline Guodong Wang et al./2017 & Endocytic PEl-Alg NPs & Endothelial progenitor cells & TEM & [128] \\
\hline Prasad Tammineni et al./2017 & $\begin{array}{l}\text { Association of soluble } A \beta \\
\text { oligomers }\end{array}$ & COS7, & Colocalization (Rab7、LC3) & [129] \\
\hline Ruud H. Wijdeven et al./2016 & Cytosolic components & Hela, HEK 293 T & $\begin{array}{l}\text { Colocalization } \\
\text { (LC3、CD63) }\end{array}$ & [123] \\
\hline Zhihua Chen et al./2016 & Endocytic Ultrafine PM & $\begin{array}{l}\text { Human bronchial epithelial } \\
\text { cells }\end{array}$ & TEM & [121] \\
\hline Sovan Sarka et al./2013 & Cholesterol & MEF & Colocalization (Rab7、LC3) & [34] \\
\hline Yusong Zhang, et al./2012 & Endocytic HMGB1 & HepG2 & Colocalization (HMGB1、LC3) & [122] \\
\hline
\end{tabular}

SIM Structured illumination microscopy, TEM Transmission electron microscopy, Immuno-EM Immuno-electron microscop, Colocalization Immunofluorescence colocalization, VEGFR2 Vascular endothelial growth factor receptor, HMGB1 High mobility group box 1

microvesicles (ARMMs) (similar to a subpopulation of exosomes) [136] originating from outward budding at the plasma membrane, with exosomes displaying the exosomal markers CD63, CD81, and CD9, derived from MVBplasma membrane fusion events $[1,15,82]$. Moreover, in human monocyte-derived macrophages (MDMs), HIV-1 buds into and accumulates on the intracellular plasma membrane-connected compartments (IPMCs, also termed virus-containing compartments) [137, 138]. IPMCs are made up of complex intracellular networks of membranes, with interconnected tubular components, and channellike connections to the cell surface, allowing them to play key roles as reservoirs of vesicle accumulation and sources for pulsatile release $[137,138]$. The vesicles (similar to a subpopulation of exosomes) from IPMCs usually expressing CD81, CD9, CD53, and CD63, are also comparable to that of exosomes and sEVs $[69,137,139]$. Such similarities make the separation of virions and exosomes from virusinfected cells particularly challenging [138, 140, 141]. Taken together, we can confirm that MVB plays an important role in the composition and characteristics of extracellular vesicles, which determines the secretion and specificity of most exosomes [2, 30, 142] (Fig. 3a).
Moreover, when discussing the effects of EVs derived from MVBs on disease, we must strictly ensure that the exosomes are of multivesicular endosomal origin to avoid exaggerating the role of MVBs in pathophysiology.

\section{MVBs in tumor progression}

MVBs are involved in promoting virtually all aspects of cancer progression, including tumor expansion, immune responses, and drug resistance $[2,28,30,71$, 143]. Studies have shown that MVBs, as important mediators of many aspects of cellular homeostasis, undergo significant changes in adapting to various stress conditions that enable cancer cells to maintain its homeostasis [3, 24, 40]. Additionally, tumor cells are generally exposed to high levels of stress, such as starvation, hypoxia, chemotherapy drugs, $\mathrm{pH}$, and various inflammatory factors $[131,144,145]$. When cancer cells need to escape unfavourable environments, on the one hand, they can release special exosomal cargo, such as nucleic acids, signalling proteins, and metabolites, and thus mediate the exchange of information between the tumor and its microenvironment $[39,142,144,146] 32$, 446,697. On the other hand, metabolic waste and 
catabolized toxic substances are released via an endosomallysosomal mechanism, which provides recycled raw materials $[30,36]$. As highlighted in the previous sections, we discuss the role of MVBs in material balance via the endosomal-lysosomal system and the release of exosomes from MVBs containing selective cargoes that participate in intercellular substance regulation, thereby producing a comprehensive perspective on the multiple roles that MVBs play in tumor progression and metastasis (Fig. 1).

\section{MVBs and metastasis in cancer}

Mounting evidence confirms that, in tumors, the key proteins involved in MVB formation, transport, fusion, and other steps are abnormally expressed, suggesting that dynamic changes to MVBs play vital roles [2, 12, 147]. For example, the abnormal expression of STX1A and VAMP2 promotes the progression and invasion of cancer cells, transforming cells into high-grade tumors in bladder cancer [147]. Valcz et al. identified the most aberrantly expressed MVB markers and revealed the transition of diffuse ALIX signals into a MVB-like pattern during the adenoma-carcinoma sequence, which may provide clues to revealing the interactions between cancer and the surrounding microenvironment, particularly those involving the regulation of tumor growth and metastatic invasion [148]. Moreover, the formation of invadopodia (see above) in many types of cancer drives cell invasion, depending on enhanced MVB docking and fusion with the plasma membrane $[85,102,149]$. Therefore, we believe that invadopodia formation is the first step in tumor cell invasion and metastasis, in which MVB-mediated transport of MMPs to degrade the extracellular matrix is an important step [85, 89, 102, 149]. A recent study revealed that VAMP3-dependent secretion of MT1-MMP enhances the degradation of the extracellular matrix, and induces cancer cell invasion [102]. Although the concept of invadopodia was not mentioned, a study showed that MVB-mediated targeting of MMPs to plasma membrane plays an important role in initiating tumor cell invasion and metastasis $[85,102]$ (Fig. 3a). Importantly, MVBs can selectively load active substances (see above) to exert protumorigenic effects on stromal cells via the paracrine or autocrine signalling $[2,29,39,146]$ (Fig. 1). For example, the secretion of extracellular vesicle-packaged HIF-1 $\alpha$ stabilizing lncRNA by tumor-associated macrophages inhibits the hydroxylation and degradation of HIF- $1 \alpha$ by blocking the interaction of prolyl hydroxylase domain 2 and HIF- $1 \alpha$ in breast cancer cells, facilitating their aerobic glycolysis and chemoresistance [39]. Hepatoma cell-derived exosomal miR-103 increases vascular permeability and facilitates metastasis by targeting multiple endothelial junction proteins [146].

\section{MVBs and immunity in cancer}

Immunotherapy has revolutionized cancer therapy, among which programmed death ligand 1 (PD-L1) has been proved to be an effective target for inhibiting tumor growth [30]. Strikingly, several studies identified that MVBs play key roles in the cell-surface expression and exosomal packaging of PD-L1 [30]. ALIX regulates the immunosuppressive properties in basal-like breast cancer (BLBC) cells by enhancing PD-L1 sorting onto ILVs and its release into the microenvironment to deplete PD-L1 surface presentation [30]. PD-L1 localized to the limiting membrane and ILVs of CD63-positive MVBs in HCC1954 cells can be degraded by lysosomes or be returned to the plasma membrane [30]. Importantly, PD-L1 on EVs may be important mediators of immunosuppression for glioblastoma and support the potential of EVs as biomarkers in glioblastoma patients [150]. Obviously, the fate of MVBs in mediating PD-L1 significantly affects the immune escape and treatment of tumors [30, 142]. Moreover, many studies have confirmed that exosomal PD-L1 plays an important role in mediating tumor metastasis, immune escape, and immunotherapy. Importantly, studies on glioblastoma, metastatic melanoma [151], breast cancer [152], and prostate cancer [142] have confirmed that exosomal PD-L1 can mediate resistance to immunotherapy by directly binding to an anti-PD-L1 antibody [153]. Remarkably, some scholars have discovered that the combination of an exosomal PD-L1 blockade and antiPD-L1 antibodies has the potential to suppress tumor growth and improve antitumour response in the clinic [142, 154]. Importantly, many receptors or membrane proteins, such as vascular endothelial growth factor receptor (VEGFR) and growth factor receptor (GFR) have the potential to undergo a similar fate as PD-L1 in tumorigenesis $[28,29,102,142]$. Manipulating the fate of MVBs is an important prospect for improved cancer treatment.

\section{MVBs and drug resistance in cancer}

Cells have the ability to antagonize drug effects through various mechanisms, and MVBs play an important role in the mechanism of cell-acquired resistance [155-157]. In particular, drug resistance is an important factor in the poor prognosis of patients with cancer; thus, the role of MVBs in drug resistance is essential $[155,158]$. In recent years, emerging evidence has suggested that MVBs selectively load exosomes containing active proteins, RNAs, and other substances to transfer drug resistance between cells [40, 155, 158]. For example, $\mathrm{Xu}$ et al. found that PSMA3 (encodes proteasome subunit $\alpha 7$ ) and lncPSMA3-AS1 can be packaged into exosomes to transfer proteasome inhibitor resistance from mesenchymal stem cells to multiple myeloma cells 
[158]. Macrophage-derived exosomes are conveyers of antagomirs, which induce gemcitabine resistance in pancreatic adenocarcinoma [40]. Moreover, MVBs can control membrane receptor recycling or degradation via the lysosomal pathway, which can alter the toxic responses of drugs on target cells [28]. Qu et al. revealed that HCC cell-derived exosomes induce sorafenib resistance [156]. Whereas, Ardelt et al. demonstrated that the MVB-mediated endocytosis of VEGFR and GFR attenuated the HCC cell response to sorafenib [28] (Fig. 1). The investigators demonstrated that arresting MVB intracellular trafficking using cyclin-dependent kinase 5 inhibitors, led to the intracellular accumulation of various cargoes that likely affected the extent and quality of VEGFR and GFR signal activation, significantly improving the efficacy of sorafenib [28]. Similarly, Dutta et al. confirmed that neuropilin 2 (NRP2) depletion impaired the endocytic transport of cell surface EGFR, which blocked the functionally active EGFR in MVBs, thereby triggering aberrant ERK activation and cell death [29].

\section{Conclusions}

This review summarizes recent progress in the research into MVBs. Initially, the mechanisms of ILV formation were discussed. Second, the sorting mechanisms of different cargoes were analyzed, with special emphasis on the possible mechanisms of sorting cargoes such as cytoplasmic proteins, RNAs, and lipids into MVBs.

Clearly, different cargoes are loaded into MVBs via a variety of methods, and the more distant cytoplasmic cargoes are not randomly targeted to MVBs, which suggests the presence of a special recruitment mechanism. Current research confirms that RNA is recruited through the facilitation of multiple RBPs (e.g., RISC). However, the only known mechanism by which cytoplasmic proteins are sorted into the lumen of MVBs involve the eMI and NVT pathways.

We also highlighted the importance the fate of mature MVBs in stimulating tumor growth, metastasis and drug resistance, and the manipulation of MVBs to treat tumors is gradually becoming a possibility. Considering on the complexity of the endosomal system, we have generated a reasonable summary of current research and speculated on the factors that might regulate the fate of MVBs. Although many mechanisms for MVB regulation are summarized, there are many details that remain to be determined, including whether there is a difference in the dominant regulatory mechanisms of MVBs in different tumors and stress situations. How can specifically manipulate the fate of MVBs to improve cancer diagnosis and therapy? Is it possible to predict tumor occurrence through early changes in the shape and content of MVBs? Consequently, exploring the exact mechanisms of MVB fate regulation in different diseases and establishing a comprehensive knowledge of MVBs are increasingly important.

Cells exhibit distinct classes of MVBs and EVs that are generated under different microenvironmental stresses. For example, under hypoxic conditions, tumour cells show changes in morphology, distribution, and accumulation cargo of MVBs and are accompanied by significant differences in the number, morphology, and cargoes of extracellular vesicles. Importantly, these changes indicate that, in different cellular contexts, the characteristics of MVBs and EVs undergo dynamic changes, creating great challenges and opportunities for understanding and treating diseases. In future research, we should pay more attention to the use of complementary methods of analysis and more accurate biomarkers to more accurately distinguish between different MVB subgroups and heterogeneous EVs, which would be beneficial for exploring whether there is a ubiquitous crosstalk mechanism involved in various MVB functions. At the same time, we also highlight the importance of MVBs in different aspects of cancer progression and metastasis for developing novel treatment strategies.

\section{Abbreviations \\ MVBs: Multivesicular bodies; EVs: Extracellular vesicles; SNAREs: Synaptosomal- associated proteins; ESCRT: Endosomal sorting complex required for transport; VPS4: Vacuolar protein sorting gene 4; MLKL: Phosphorylated mixed lineage kinase domain like pseudokinase; HRS: Hepatocyte growth factor-regulated tyrosine kinase substrate; NSF: N-ethylmaleimide-sensitive factor; PIPKlyi5: Phosphatidylinositol-4-phosphate 5-kinase type 1 gamma; TSG101: Tumor suppressor gene 101 protein; PTMs: Post-translational modifications; PD-L1: Programmed death ligand 1; RBPS: RNA-binding proteins; hnRNPA2B1: Heterogeneous nuclear ribonucleoprotein A2B1; VAMP: Vesicle-associated membrane protein; VEGFR: Vascular endothelial growth factor receptor}

\section{Acknowledgements}

We thank Fuhui Zhang for kindly provided images.

\section{Authors' contributions}

$X P, L Y, Y M, Y L$ and $H L$ conceived the review and participated in its design. $X P$ and $H L$ wrote the manuscript. The authors read and approved the final manuscript.

\section{Funding}

This work was supported by grants from the National Natural Science Foundation of China (No. 81472302).

\section{Availability of data and materials \\ Other datasets analyzed during the current study are available from the corresponding author on reasonable request.}

Ethics approval and consent to participate

Not applicable.

Consent for publication

Not applicable.

Competing interests

The authors declare that they have no competing interests. 
Received: 9 April 2020 Accepted: 27 June 2020

\section{Published online: 08 August 2020}

\section{References}

1. Hyenne V, Apaydin A, Rodriguez D, Spiegelhalter C, Hoff-Yoessle S, Diem M, et al. RAL-1 controls multivesicular body biogenesis and exosome secretion. J Cell Biol. 2015:211(1):27-37.

2. Hanson PI, Cashikar A. Multivesicular body morphogenesis. Annu Rev Cell Dev Biol. 2012:28:337-62

3. Altick AL, Baryshnikova LM, Vu TQ, von Bartheld CS. Quantitative analysis of multivesicular bodies (MVBs) in the hypoglossal nerve: evidence that neurotrophic factors do not use MVBs for retrograde axonal transport. J Comp Neurol. 2009;514(6):641-57.

4. Von Bartheld CS, Altick AL. Multivesicular bodies in neurons: distribution, protein content, and trafficking functions. Prog Neurobiol. 2011;93(3):313-40.

5. Kalluri R, LeBleu VS. The biology, function, and biomedical applications of exosomes. Science (New York, NY). 2020;367(6478):eaau6977.

6. Cai Q, Qiao L, Wang M, He B, Lin FM, Palmquist J, et al. Plants send small RNAs in extracellular vesicles to fungal pathogen to silence virulence genes. Science (New York, NY). 2018;360(6393):1126-9.

7. Teng Y, Ren Y, Sayed M, Hu X, Lei C, Kumar A, et al. Plant-derived Exosomal MicroRNAs shape the gut microbiota. Cell Host Microbe. 2018;24(5):637-52.e8.

8. Jung YS, Jun S, Kim MJ, Lee SH, Suh HN, Lien EM, et al. TMEM9 promotes intestinal tumorigenesis through vacuolar-ATPase-activated Wnt/betacatenin signalling. Nat Cell Biol. 2018;20(12):1421-33.

9. Eitan E, Suire C, Zhang S, Mattson MP. Impact of lysosome status on extracellular vesicle content and release. Ageing Res Rev. 2016;32:65-74.

10. Latifkar A, Ling L, Hingorani A, Johansen E, Clement A, Zhang X, et al. Loss of Sirtuin 1 alters the Secretome of breast cancer cells by impairing lysosomal integrity. Dev Cell. 2019;49(3):393-408.e7.

11. Yoon S, Kovalenko A, Bogdanov K, Wallach D. MLKL, the protein that mediates necroptosis, also regulates endosomal trafficking and extracellular vesicle generation. Immunity. 2017;47(1):51-65.e7.

12. Zhu J, Liu YF, Zhang YP, Zhao CR, Yao WJ, Li YS, et al. VAMP3 and SNAP23 mediate the disturbed flow-induced endothelial microRNA secretion and smooth muscle hyperplasia. Proc Natl Acad Sci U S A. 2017;114(31):8271-6.

13. Jeppesen DK, Fenix AM, Franklin JL, Higginbotham JN, Zhang Q, Zimmerman $\sqcup$, et al. Reassessment of exosome composition. Cell. 2019; 177(2):428-45.e18.

14. Verweij FJ, Bebelman MP, Jimenez CR, Garcia-Vallejo JJ, Janssen H, Neefjes J, et al. Quantifying exosome secretion from single cells reveals a modulatory role for GPCR signaling. J Cell Biol. 2018;217(3):1129-42.

15. Wei $Y$, Wang D, Jin F, Bian Z, Li L, Liang H, et al. Pyruvate kinase type M2 promotes tumour cell exosome release via phosphorylating synaptosomeassociated protein 23. Nat Commun. 2017;8:14041.

16. Koike $S$, Jahn R. SNAREs define targeting specificity of trafficking vesicles by combinatorial interaction with tethering factors. Nat Commun. 2019;10(1):1608.

17. van Niel G, D'Angelo G, Raposo G. Shedding light on the cell biology of extracellular vesicles. Nat Rev Mol Cell Biol. 2018;19(4):213-28.

18. Hessvik NP, Llorente A. Current knowledge on exosome biogenesis and release. Cellular Mol Life Sci CMLS. 2018;75(2):193-208.

19. Maas SLN, Breakefield XO, Weaver AM. Extracellular vesicles: unique intercellular delivery vehicles. Trends Cell Biol. 2017;27(3):172-88.

20. Kossinova OA, Gopanenko AV, Tamkovich SN, Krasheninina OA, Tupikin AE,

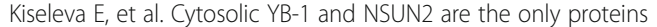
recognizing specific motifs present in mRNAs enriched in exosomes. Biochim Biophys Acta Proteins Proteomics. 2017;1865(6):664-73.

21. Skotland T, Hessvik NP, Sandvig K, Llorente A. Exosomal lipid composition and the role of ether lipids and phosphoinositides in exosome biology. J Lipid Res. 2019;60(1):9-18.

22. Wang S, Thibault G, Ng DT. Routing misfolded proteins through the multivesicular body (MVB) pathway protects against proteotoxicity. J Biol Chem. 2011;286(33):29376-87.

23. Villarroya-Beltri C, Baixauli F, Gutierrez-Vazquez C, Sanchez-Madrid F, Mittelbrunn M. Sorting it out: regulation of exosome loading. Semin Cancer Biol. 2014:28:3-13.

24. Mathieu M, Martin-Jaular L, Lavieu G, Thery C. Specificities of secretion and uptake of exosomes and other extracellular vesicles for cell-to-cell communication. Nat Cell Biol. 2019;21(1):9-17.
25. Babst M, Odorizzi G. The balance of protein expression and degradation: an ESCRTs point of view. Curr Opin Cell Biol. 2013;25(4):489-94.

26. Obata Y, Kita S, Koyama Y, Fukuda S, Takeda H, Takahashi M, et al. Adiponectin/T-cadherin system enhances exosome biogenesis and decreases cellular ceramides by exosomal release. JCl insight. 2018;3(8): e99680.

27. Zou W, Lai M, Zhang Y, Zheng L, Xing Z, Li T, et al. Exosome release is regulated by mTORC1. Adv Sci (Weinheim, Baden-Wurttemberg, Germany). 2019:6(3):1801313.

28. Ardelt MA, Frohlich T, Martini E, Muller M, Kanitz V, Atzberger C, et al. Inhibition of cyclin-dependent kinase 5: a strategy to improve Sorafenib response in hepatocellular carcinoma therapy. Hepatology (Baltimore, Md). 2019:69(1):376-93.

29. Dutta S, Roy S, Polavaram NS, Stanton MJ, Zhang H, Bhola T, et al. Neuropilin-2 regulates endosome maturation and EGFR trafficking to support cancer cell pathobiology. Cancer Res. 2016;76(2):418-28.

30. Monypenny J, Milewicz H, Flores-Borja F, Weitsman G, Cheung A, Chowdhury $R$, et al. ALIX regulates tumor-mediated immunosuppression by controlling EGFR activity and PD-L1 presentation. Cell Rep. 2018;24(3):630-41.

31. Adell MA, Vogel GF, Pakdel M, Muller M, Lindner H, Hess MW, et al. Coordinated binding of Vps4 to ESCRT-III drives membrane neck constriction during MVB vesicle formation. J Cell Biol. 2014;205(1):33-49.

32. Dutta D, Donaldson JG. Sorting of Clathrin-independent cargo proteins depends on Rab35 delivered by Clathrin-mediated endocytosis. Traffic (Copenhagen, Denmark). 2015;16(9):994-1009.

33. Sun Y, Hedman AC, Tan X, Schill NJ, Anderson RA. Endosomal type Igamma PIP 5-kinase controls EGF receptor lysosomal sorting. Dev Cell. 2013;25(2):144-55.

34. Sarkar S, Carroll B, Buganim Y, Maetzel D, Ng AH, Cassady JP, et al. Impaired autophagy in the lipid-storage disorder Niemann-pick type C1 disease. Cell Rep. 2013;5(5):1302-15.

35. Babst M. Quality control: quality control at the plasma membrane: one mechanism does not fit all. J Cell Biol. 2014;205(1):11-20.

36. Heisler FF, Pechmann Y, Wieser I, Altmeppen HC, Veenendaal L, Muhia M, et al. Muskelin coordinates $\operatorname{Pr} P(C)$ lysosome versus exosome targeting and impacts prion disease progression. Neuron. 2018;99(6):1155-69.e9.

37. Barbero-Camps E, Roca-Agujetas V, Bartolessis I, de Dios C, Fernandez-Checa JC, Mari M, et al. Cholesterol impairs autophagy-mediated clearance of amyloid beta while promoting its secretion. Autophagy. 2018;14(7):1129-54.

38. Wang K, Wei Y, Liu W, Liu L, Guo Z, Fan C, et al. Mechanical stressdependent autophagy component release via extracellular Nanovesicles in tumor cells. ACS Nano. 2019;13(4):4589-602

39. Chen F, Chen J, Yang L, Liu J, Zhang X, Zhang Y, et al. Extracellular vesiclepackaged HIF-1alpha-stabilizing IncRNA from tumour-associated macrophages regulates aerobic glycolysis of breast cancer cells. Nat Cell Biol. 2019:21(4):498-510.

40. Binenbaum Y, Fridman E, Yaari Z, Milman N, Schroeder A, Ben David G, et al Transfer of miRNA in macrophage-derived exosomes induces drug resistance in pancreatic adenocarcinoma. Cancer Res. 2018;78(18):5287-99.

41. Edgar JR, Eden ER, Futter CE. Hrs- and CD63-dependent competing mechanisms make different sized endosomal intraluminal vesicles. Traffic (Copenhagen, Denmark). 2014;15(2):197-211.

42. MCNally EK, Brett CL. The intralumenal fragment pathway mediates ESCRTindependent surface transporter down-regulation. Nat Commun. 2018;9(1): 5358.

43. Frankel EB, Audhya A. ESCRT-dependent cargo sorting at multivesicular endosomes. Semin Cell Dev Biol. 2018;74:4-10.

44. Wenzel EM, Schultz SW, Schink KO, Pedersen NM, Nahse V, Carlson A, et al. Concerted ESCRT and clathrin recruitment waves define the timing and morphology of intraluminal vesicle formation. Nat Commun. 2018;9(1):2932.

45. Coulter ME, Dorobantu CM, Lodewijk GA, Delalande F, Cianferani S, Ganesh VS, et al. The ESCRT-III protein CHMP1A mediates secretion of sonic hedgehog on a distinctive subtype of extracellular vesicles. Cell Rep. 2018, 24(4):973-86.e8

46. Sun S, Zhou X, Zhang W, Gallick GE, Kuang J. Unravelling the pivotal role of Alix in MVB sorting and silencing of the activated EGFR. Biochem J. 2015; 466(3):475-87.

47. Blander JM. The comings and goings of MHC class I molecules herald a new dawn in cross-presentation. Immunol Rev. 2016;272(1):65-79.

48. Kajimoto T, Okada T, Miya S, Zhang L, Nakamura S. Ongoing activation of sphingosine 1-phosphate receptors mediates maturation of exosomal multivesicular endosomes. Nat Commun. 2013;4:2712. 
49. Trajkovic K, Hsu C, Chiantia S, Rajendran L, Wenzel D, Wieland F, et al. Ceramide triggers budding of exosome vesicles into multivesicular endosomes. Science (New York, NY). 2008:319(5867):1244-7.

50. Verderio C, Gabrielli M, Giussani P. Role of sphingolipids in the biogenesis and biological activity of extracellular vesicles. J Lipid Res. 2018;59(8):1325-40.

51. Im EJ, Lee $\mathrm{CH}$, Moon PG, Rangaswamy GG, Lee B, Lee JM, et al. Sulfisoxazole inhibits the secretion of small extracellular vesicles by targeting the endothelin receptor a. Nat Commun. 2019;10(1):1387.

52. Deng $L$, Jiang W, Wang X, Merz A, Hiet MS, Chen Y, et al. Syntenin regulates hepatitis $C$ virus sensitivity to neutralizing antibody by promoting E2 secretion through exosomes. J Hepatol. 2019;71(1):52-61.

53. Ghossoub R, Lembo F, Rubio A, Gaillard CB, Bouchet J, Vitale N, et al. Syntenin-ALIX exosome biogenesis and budding into multivesicular bodies are controlled by ARF6 and PLD2. Nat Commun. 2014;5:3477.

54. Stoorvogel W. Resolving sorting mechanisms into exosomes. Cell Res. 2015; 25(5):531-2

55. Larios J, Mercier V, Roux A, Gruenberg J. ALIX- and ESCRT-III-dependent sorting of tetraspanins to exosomes. J Cell Biol. 2020;219(3):e201904113.

56. van Niel G, Charrin S, Simoes S, Romao M, Rochin L, Saftig P, et al. The tetraspanin CD63 regulates ESCRT-independent and -dependent endosomal sorting during melanogenesis. Dev Cell. 2011;21(4):708-21.

57. Leidal AM, Debnath J. Unraveling the mechanisms that specify molecules for secretion in extracellular vesicles. Methods. 2020:S1046-2023(19):30286-5.

58. Ageta H, Ageta-Ishihara N, Hitachi K, Karayel O, Onouchi T, Yamaguchi H, et al. UBL3 modification influences protein sorting to small extracellular vesicles. Nat Commun. 2018;9(1):3936.

59. Moreno-Gonzalo O, Fernandez-Delgado I, Sanchez-Madrid F. Posttranslational add-ons mark the path in exosomal protein sorting. Cellular Mol Life Sciences : CMLS. 2018;75(1):1-19.

60. Cotzomi-Ortega I, Aguilar-Alonso P, Reyes-Leyva J, Maycotte P. Autophagy and its role in protein secretion: implications for cancer therapy. Mediators Inflamm. 2018:2018:4231591.

61. Lefebvre C, Legouis R, Culetto E. ESCRT and autophagies: endosomal functions and beyond. Semin Cell Dev Biol. 2018;74:21-8.

62. Albrecht LV, Ploper D, Tejeda-Munoz N, De Robertis EM. Arginine methylation is required for canonical Wnt signaling and endolysosomal trafficking. Proc Natl Acad Sci U S A. 2018;115(23):E5317-e25.

63. Mejlvang J, Olsvik H, Svenning S, Bruun JA, Abudu YP, Larsen KB, et al. Starvation induces rapid degradation of selective autophagy receptors by endosomal microautophagy. J Cell Biol. 2018;217(10):3640-55.

64. Hessvik NP, Overbye A, Brech A, Torgersen ML, Jakobsen IS, Sandvig K, et al. PIKfyve inhibition increases exosome release and induces secretory autophagy. Cellular Mol Life Sci CMLS. 2016;73(24):4717-37.

65. Mukherjee A, Patel B, Koga H, Cuervo AM, Jenny A. Selective endosomal microautophagy is starvation-inducible in drosophila. Autophagy. 2016; 12(11):1984-99.

66. Mizushima N. Nbr1, a receptor for ESCRT-dependent endosomal microautophagy in fission yeast. Mol Cell. 2015;59(6):887-9.

67. McKenzie AJ, Hoshino D, Hong NH, Cha DJ, Franklin JL, Coffey RJ, et al. KRAS-MEK signaling controls Ago2 sorting into exosomes. Cell Rep. 2016; 15(5):978-87.

68. Santangelo L, Giurato G, Cicchini C, Montaldo C, Mancone C, Tarallo R, et al. The RNA-binding protein SYNCRIP is a component of the hepatocyte Exosoma machinery controlling MicroRNA sorting. Cell Rep. 2016;17(3):799-808.

69. Pegtel DM, Gould SJ. Exosomes. Annu Rev Biochem. 2019;88:487-514.

70. Leidal AM, Huang HH, Marsh T, Solvik T, Zhang D, Ye J, et al. The LC3conjugation machinery specifies the loading of RNA-binding proteins into extracellular vesicles. Nat Cell Biol. 2020;22(2):187-99.

71. O'Brien K, Breyne K, Ughetto S, Laurent LC, Breakefield XO. RNA delivery by extracellular vesicles in mammalian cells and its applications. Nat Rev Mol Cell Biol. 2020;26:1-22.

72. Teng Y, Ren Y, Hu X, Mu J, Samykutty A, Zhuang X, et al. MVP-mediated exosomal sorting of miR-193a promotes colon cancer progression. Nat Commun. 2017:8:14448.

73. Villarroya-Beltri C, Gutiérrez-Vázquez C, Sánchez-Cabo F, Pérez-Hernández D, Vázquez J, Martin-Cofreces N, et al. Sumoylated hnRNPA2B1 controls the sorting of miRNAs into exosomes through binding to specific motifs. Nat Commun. 2013:4:2980.

74. Hinger SA, Cha DJ, Franklin JL, Higginbotham JN, Dou Y, Ping J, et al. Diverse long RNAs are differentially sorted into extracellular vesicles secreted by colorectal cancer cells. Cell Rep. 2018;25(3):715-25.e4.
75. Siomi H, Siomi MC. RISC hitches onto endosome trafficking. Nat Cell Biol. 2009;11(9):1049-51.

76. Hobor F, Dallmann A, Ball NJ, Cicchini C, Battistelli C, Ogrodowicz RW, et al. A cryptic RNA-binding domain mediates Syncrip recognition and exosomal partitioning of miRNA targets. Nat Commun. 2018;9(1):831.

77. Shurtleff MJ, Temoche-Diaz MM, Karfilis KV, Ri S, Schekman R. Y-box protein 1 is required to sort microRNAs into exosomes in cells and in a cell-free reaction. eLife. 2016;5:e19276.

78. Janas T, Janas MM, Sapoń K, Janas T. Mechanisms of RNA loading into exosomes. FEBS Lett. 2015;589(13):1391-8.

79. Xu R, Greening DW, Chen M, Rai A, Ji H, Takahashi N, et al. Surfaceome of exosomes secreted from the colorectal cancer cell line SW480: peripheral and integral membrane proteins analyzed by proteolysis and TX114. Proteomics. 2019;19(8):e1700453.

80. Heusermann W, Hean J, Trojer D, Steib E, von Bueren S, Graff-Meyer A, et al. Exosomes surf on filopodia to enter cells at endocytic hot spots, traffic within endosomes, and are targeted to the ER. J Cell Biol. 2016:213(2):173-84.

81. Villarroya-Beltri C, Baixauli F, Mittelbrunn M, Fernandez-Delgado I, Torralba D, Moreno-Gonzalo O, et al. ISGylation controls exosome secretion by promoting lysosomal degradation of MVB proteins. Nat Commun. 2016;7:13588.

82. Song L, Tang S, Han X, Jiang Z, Dong L, Liu C, et al. KIBRA controls exosome secretion via inhibiting the proteasomal degradation of Rab27a. Nat Commun. 2019;10(1):1639.

83. Babuta M, Furi I, Bala S, Bukong TN, Lowe P, Catalano D, et al. Dysregulated autophagy and lysosome function are linked to exosome production via miR-155 in alcoholic liver disease. Hepatology (Baltimore, Md). 2019;70(6): 2123-41.

84. Sinha S, Hoshino D, Hong NH, Kirkbride KC, Grega-Larson NE, Seiki M, et al. Cortactin promotes exosome secretion by controlling branched actin dynamics. J Cell Biol. 2016;214(2):197-213.

85. Hoshino D, Kirkbride KC, Costello K, Clark ES, Sinha S, Grega-Larson N, et al. Exosome secretion is enhanced by invadopodia and drives invasive behavior. Cell Rep. 2013;5(5):1159-68.

86. Wen PJ, Grenklo S, Arpino G, Tan X, Liao HS, Heureaux J, et al. Actin dynamics provides membrane tension to merge fusing vesicles into the plasma membrane. Nat Commun. 2016;7:12604.

87. Martin-Cofreces NB, Baixauli F, Sanchez-Madrid F. Immune synapse: conductor of orchestrated organelle movement. Trends Cell Biol. 2014;24(1): $61-72$.

88. Olenick MA, Holzbaur ELF. Dynein activators and adaptors at a glance. J Cell Sci. 2019;132(6):jcs227132.

89. Messenger SW, Woo SS, Sun Z, Martin TFJ. A ca (2+)-stimulated exosome release pathway in cancer cells is regulated by Munc13-4. J Cell Biol. 2018; 217(8):2877-90.

90. Stenmark H. Rab GTPases as coordinators of vesicle traffic. Nat Rev Mol Cell Biol. 2009;10(8):513-25.

91. Hsu C, Morohashi Y, Yoshimura S, Manrique-Hoyos N, Jung S, Lauterbach MA, et al. Regulation of exosome secretion by Rab35 and its GTPaseactivating proteins TBC1D10A-C. J Cell Biol. 2010;189(2):223-32.

92. Ostrowski M, Carmo NB, Krumeich S, Fanget I, Raposo G, Savina A, et al. Rab27a and Rab27b control different steps of the exosome secretion pathway. Nat Cell Biol. 2010;12(1):19-30 sup pp 1-13.

93. Johnson JL, He J, Ramadass M, Pestonjamasp K, Kiosses WB, Zhang J, et al Munc13-4 is a Rab11-binding protein that regulates Rab11-positive vesicle trafficking and docking at the plasma membrane. J Biol Chem. 2016;291(7): 3423-38.

94. Yang L, Peng $X, L i Y$, Zhang $X, M a ~ Y$, Wu $C$, et al. Long non-coding RNA HOTAIR promotes exosome secretion by regulating RAB35 and SNAP23 in hepatocellular carcinoma. Mol Cancer. 2019;18(1):78.

95. Bonifacino JS, Neefjes J. Moving and positioning the endolysosomal system. Curr Opin Cell Biol. 2017:47:1-8

96. Yang J, Zhang Z, Zhang Y, Ni X, Zhang G, Cui X, et al. ZIP4 promotes muscle wasting and cachexia in mice with Orthotopic pancreatic tumors by stimulating RAB27B-regulated release of extracellular vesicles from cancer cells. Gastroenterology. 2019;156(3):722-34.e6.

97. Bentley M, Decker H, Luisi J, Banker G. A novel assay reveals preferential binding between Rabs, kinesins, and specific endosomal subpopulations. J Cell Biol. 2015;208(3):273-81.

98. Majumder P, Chakrabarti O. Mahogunin regulates fusion between amphisomes/MVBs and lysosomes via ubiquitination of TSG101. Cell Death Dis. 2015;6:e1970. 
99. Sapmaz A, Berlin I, Bos E, Wijdeven RH, Janssen H, Konietzny R, et al. USP32 regulates late endosomal transport and recycling through deubiquitylation of Rab7. Nat Commun. 2019;10(1):1454.

100. Ahmed SM, Nishida-Fukuda H, Li Y, McDonald WH, Gradinaru CC, Macara IG. Exocyst dynamics during vesicle tethering and fusion. Nat Commun. 2018; 9(1):5140.

101. Hong W, Lev S. Tethering the assembly of SNARE complexes. Trends Cell Biol. 2014;24(1):35-43.

102. Sneeggen M, Pedersen NM, Campsteijn C, Haugsten EM, Stenmark H, Schink KO. WDFY2 restrains matrix metalloproteinase secretion and cell invasion by controlling VAMP3-dependent recycling. Nat Commun. 2019; 10(1):2850

103. Mei K, Guo W. Exocytosis: a New exocyst movie. Current Biol. 2019;29(1): R30-r2.

104. Lauwers E, Wang YC, Gallardo R, Van der Kant R, Michiels E, Swerts J, et al. Hsp90 mediates membrane deformation and exosome release. Mol Cell. 2018;71(5):689-702.e9.

105. Gu H, Chen C, Hao X, Wang C, Zhang X, Li Z, et al. Sorting protein VPS33B regulates exosomal autocrine signaling to mediate hematopoiesis and leukemogenesis. J Clin Invest. 2016;126(12):4537-53.

106. Gissen P, Johnson CA, Morgan NV, Stapelbroek JM, Forshew T, Cooper WN, et al. Mutations in VPS33B, encoding a regulator of SNARE-dependent membrane fusion, cause arthrogryposis-renal dysfunction-cholestasis (ARC) syndrome. Nat Genet. 2004;36(4):400-4.

107. Baker RW, Jeffrey PD, Zick M, Phillips BP, Wickner WT, Hughson FM. A direct role for the Sec1/Munc18-family protein Vps33 as a template for SNARE assembly. Science (New York, NY). 2015;349(6252):1111-4.

108. Weddell JC, Imoukhuede PI. Integrative meta-modeling identifies endocytic vesicles, late endosome and the nucleus as the cellular compartments primarily directing RTK signaling. Integrative Biol. 2017;9(5):464-84.

109. Cotter K, Stransky L, McGuire C, Forgac M. Recent insights into the structure, regulation, and function of the V-ATPases. Trends Biochem Sci. 2015;40(10): 611-22.

110. Grimm C, Chen CC, Wahl-Schott C, Biel M. Two-pore channels: catalyzers of Endolysosomal transport and function. Front Pharmacol. 2017;8:45.

111. Stransky L, Cotter K, Forgac M. The function of V-ATPases in cancer. Physiol Rev. 2016;96(3):1071-91.

112. Hiesinger $P R$, Fayyazuddin $A$, Mehta $S Q$, Rosenmund $T$, Schulze $K L$, Zhai $R G$, et al. The $\mathrm{V}$-ATPase $\mathrm{V} 0$ subunit a1 is required for a late step in synaptic vesicle exocytosis in drosophila. Cell. 2005:121(4):607-20.

113. Liegeois S, Benedetto A, Garnier JM, Schwab Y, Labouesse M. The V0-ATPase mediates apical secretion of exosomes containing hedgehog-related proteins in Caenorhabditis elegans. J Cell Biol. 2006;173(6):949-61.

114. Cadwell K, Debnath J. Beyond self-eating: the control of nonautophagic functions and signaling pathways by autophagy-related proteins. J Cell Biol. 2018;217(3):813-22.

115. New J, Thomas SM. Autophagy-dependent secretion: mechanism, factors secreted, and disease implications. Autophagy. 2019;15(10):1682-93.

116. Zhao XL, Lin Y, Jiang J, Tang Z, Yang S, Lu L, et al. High-mobility group box 1 released by autophagic cancer-associated fibroblasts maintains the stemness of luminal breast cancer cells. J Pathol. 2017;243(3):376-89.

117. Berg TO, Fengsrud M, Stromhaug PE, Berg T, Seglen PO. Isolation and characterization of rat liver amphisomes. Evidence for fusion of autophagosomes with both early and late endosomes. J Biol Chem. 1998; 273(34):21883-92.

118. Fader CM, Sanchez D, Furlan M, Colombo MI. Induction of autophagy promotes fusion of multivesicular bodies with autophagic vacuoles in $\mathrm{k562}$ cells. Traffic (Copenhagen, Denmark). 2008;9(2):230-50.

119. Minakaki G, Menges S, Kittel A, Emmanouilidou E, Schaeffner I, Barkovits K, et al. Autophagy inhibition promotes SNCA/alpha-synuclein release and transfer via extracellular vesicles with a hybrid autophagosome-exosomelike phenotype. Autophagy. 2018;14(1):98-119.

120. Poehler AM, Xiang W, Spitzer $P$, May VE, Meixner $H$, Rockenstein $E$, et al. Autophagy modulates SNCA/alpha-synuclein release, thereby generating a hostile microenvironment. Autophagy. 2014;10(12):2171-92

121. Chen ZH, Wu YF, Wang PL, Wu YP, Li ZY, Zhao Y, et al. Autophagy is essential for ultrafine particle-induced inflammation and mucus hyperproduction in airway epithelium. Autophagy. 2016;12(2):297-311.

122. Zhang Y, Li W, Zhu S, Jundoria A, Li J, Yang H, et al. Tanshinone IIA sodium sulfonate facilitates endocytic HMGB1 uptake. Biochem Pharmacol. 2012; 84(11):1492-500
123. Wijdeven $R H$, Janssen $H$, Nahidiazar $L$, Janssen $L$, Jalink $K$, Berlin I, et al. Cholesterol and ORP1L-mediated ER contact sites control autophagosome transport and fusion with the endocytic pathway. Nat Commun. 2016;7: 11808.

124. Ponpuak M, Mandell MA, Kimura T, Chauhan S, Cleyrat C, Deretic V. Secretory autophagy. Curr Opin Cell Biol. 2015;35:106-16.

125. Atienzar-Aroca S, Serrano-Heras G, Freire Valls A, Ruiz de Almodovar C, Muriach $\mathrm{M}$, Barcia JM, et al. Role of retinal pigment epithelium-derived exosomes and autophagy in new blood vessel formation. J Cell Mol Med. 2018;22(11):5244-56

126. Chen YD, Fang YT, Cheng YL, Lin CF, Hsu LJ, Wang SY, et al. Exophagy of annexin $A 2$ via RAB11, RAB8A and RAB27A in IFN-gamma-stimulated lung epithelial cells. Sci Rep. 2017:7(1):5676.

127. Amengual J, Guo L, Strong A, Madrigal-Matute J, Wang H, Kaushik S, et al. Autophagy is required for Sortilin-mediated degradation of apolipoprotein B100. Circ Res. 2018;122(4):568-82.

128. Wang GD, Tan YZ, Wang HJ, Zhou P. Autophagy promotes degradation of polyethyleneimine-alginate nanoparticles in endothelial progenitor cells. Int J Nanomedicine. 2017:12:6661-75.

129. Tammineni P, Ye X, Feng T, Aikal D, Cai Q. Impaired retrograde transport of axonal autophagosomes contributes to autophagic stress in Alzheimer's disease neurons. eLife. 2017;6:e21776.

130. Garofalo M, Villa A, Crescenti D, Marzagalli M, Kuryk L, Limonta P, et al. Heterologous and cross-species tropism of cancer-derived extracellular vesicles. Theranostics. 2019;9(19):5681-93.

131. Tkach M, Thery C. Communication by extracellular vesicles: where we are and where we need to go. Cell. 2016;164(6):1226-32.

132. Meldolesi J. Exosomes and Ectosomes in intercellular communication. Current Biol. 2018;28(8):R435-r44.

133. Ma L, Li Y, Peng J, Wu D, Zhao X, Cui Y, et al. Discovery of the migrasome, an organelle mediating release of cytoplasmic contents during cell migration. Cell Res. 2015;25(1):24-38.

134. Fertig ET, Gherghiceanu M, Popescu LM. Extracellular vesicles release by cardiac telocytes: electron microscopy and electron tomography. J Cell Mol Med. 2014;18(10):1938-43.

135. Valcz G, Buzas El, Kittel A, Krenacs T, Visnovitz T, Spisak S, et al. En bloc release of MVB-like small extracellular vesicle clusters by colorectal carcinoma cells. J Extracellular Vesicles. 2019;8(1):1596668.

136. Nabhan JF, Hu R, Oh RS, Cohen SN, Lu Q. Formation and release of arrestin domain-containing protein 1-mediated microvesicles (ARMMs) at plasma membrane by recruitment of TSG101 protein. Proc Natl Acad Sci U S A. 2012;109(11):4146-51.

137. Deneka M, Pelchen-Matthews A, Byland R, Ruiz-Mateos E, Marsh M. In macrophages, HIV-1 assembles into an intracellular plasma membrane domain containing the tetraspanins CD81, CD9, and CD53. J Cell Biol. 2007; 177(2):329-41.

138. Leymarie $\mathrm{O}$, Lepont L, Versapuech $\mathrm{M}$, Judith $\mathrm{D}$, Abelanet $\mathrm{S}$, Janvier $\mathrm{K}$, et al. Contribution of the cytoplasmic determinants of vpu to the expansion of virus-containing compartments in HIV-1-infected macrophages. J Virol. 2019; 93(11):e00020-19.

139. Nardacci R, Amendola A, Ciccosanti F, Corazzari M, Esposito V, Vlassi C, et al, Autophagy plays an important role in the containment of HIV-1 in nonprogressor-infected patients. Autophagy. 2014:10(7):1167-78.

140. Zhang H, Freitas D, Kim HS, Fabijanic K, Li Z, Chen H, et al. Identification of distinct nanoparticles and subsets of extracellular vesicles by asymmetric flow field-flow fractionation. Nat Cell Biol. 2018;20(3):332-43.

141. Bello-Morales R, Lopez-Guerrero JA. Isolation/analysis of extracellular microvesicles from HSV-1-infected cells. Methods Mol Biology (Clifton, NJ). 2020;2060:305-17.

142. Poggio M, Hu T, Pai CC, Chu B, Belair CD, Chang A, et al. Suppression of Exosomal PD-L1 induces systemic anti-tumor immunity and memory. Cell. 2019:177(2):414-27.e13.

143. Armacki M, Polaschek S, Waldenmaier M, Morawe M, Ruhland C, Schmid R, et al. Protein kinase D1, reduced in human pancreatic tumors, increases secretion of small extracellular vesicles from cancer cells that promote metastasis to lung in mice. Gastroenterology. 2020:S0016-5085(20)34705-3.

144. Huang T, Song C, Zheng L, Xia L, Li Y, Zhou Y. The roles of extracellular vesicles in gastric cancer development, microenvironment, anti-cancer drug resistance, and therapy. Mol Cancer. 2019;18(1):62.

145. Sahoo S, Losordo DW. Exosomes and cardiac repair after myocardial infarction. Circ Res. 2014;114(2):333-44. 
146. Fang JH, Zhang ZJ, Shang LR, Luo YW, Lin YF, Yuan Y, et al. Hepatoma cellsecreted exosomal microRNA-103 increases vascular permeability and promotes metastasis by targeting junction proteins. Hepatology (Baltimore, Md). 2018;68(4):1459-75.

147. Raja SA, Abbas S, Shah STA, Tariq A, Bibi N, Yousuf A, et al. Increased expression levels of Syntaxin $1 \mathrm{~A}$ and Synaptobrevin 2/vesicle-associated membrane Protein-2 are associated with the progression of bladder cancer. Genet Mol Biol. 2019:42(1):40-7.

148. Valcz G, Galamb O, Krenacs T, Spisak S, Kalmar A, Patai AV, et al. Exosomes in colorectal carcinoma formation: ALIX under the magnifying glass. Modern Pathol. 2016;29(8):928-38.

149. Ji K, Mayernik L, Moin K, Sloane BF. Acidosis and proteolysis in the tumor microenvironment. Cancer Metastasis Rev. 2019;38(1-2):103-12.

150. Ricklefs FL, Alayo Q, Krenzlin H, Mahmoud AB, Speranza MC, Nakashima H, et al. Immune evasion mediated by PD-L1 on glioblastoma-derived extracellular vesicles. Sci Adv. 2018;4(3):eaar2766.

151. Yamazaki N, Takenouchi T, Fujimoto M, Ihn H, Uchi H, Inozume T, et al. Phase 1b study of pembrolizumab (MK-3475; anti-PD-1 monoclonal antibody) in Japanese patients with advanced melanoma (KEYNOTE-041). Cancer Chemother Pharmacol. 2017;79(4):651-60.

152. Yang Y, Li CW, Chan LC, Wei Y, Hsu JM, Xia W, et al. Exosomal PD-L1 harbors active defense function to suppress $T$ cell killing of breast cancer cells and promote tumor growth. Cell Res. 2018;28(8):862-4.

153. Xie F, Xu M, Lu J, Mao L, Wang S. The role of exosomal PD-L1 in tumor progression and immunotherapy. Mol Cancer. 2019;18(1):146.

154. Chen G, Huang AC, Zhang W, Zhang G, Wu M, Xu W, et al. Exosomal PD-L1 contributes to immunosuppression and is associated with anti-PD-1 response. Nature. 2018;560(7718):382-6.

155. Namee NM, O'Driscoll L. Extracellular vesicles and anti-cancer drug resistance. Biochim Biophys Acta Rev Cancer. 2018;1870(2):123-36.

156. Qu Z, Wu J, Wu J, Luo D, Jiang C, Ding Y. Exosomes derived from HCC cells induce sorafenib resistance in hepatocellular carcinoma both in vivo and in vitro. J Exper Clin Cancer Res CR. 2016;35(1):159.

157. Wang P, Wang H, Huang Q, Peng C, Yao L, Chen $H$, et al. Exosomes from M1-polarized macrophages enhance paclitaxel antitumor activity by activating macrophages-mediated inflammation. Theranostics. 2019;9(6): 1714-27.

158. Xu J, Meng Q, Li X, Yang H, Xu J, Gao N, et al. Long noncoding RNA MIR17HG promotes colorectal cancer progression via miR-17-5p. Cancer Res. 2019;79(19):4882-95.

\section{Publisher's Note}

Springer Nature remains neutral with regard to jurisdictional claims in published maps and institutional affiliations.

Ready to submit your research? Choose BMC and benefit from:

- fast, convenient online submission

- thorough peer review by experienced researchers in your field

- rapid publication on acceptance

- support for research data, including large and complex data types

- gold Open Access which fosters wider collaboration and increased citations

- maximum visibility for your research: over $100 \mathrm{M}$ website views per year

At $\mathrm{BMC}$, research is always in progress.

Learn more biomedcentral.com/submissions 